\title{
A relação entre escolaridade e uso do computador: aspectos quantitativos de um estudo de caso junto a adultos pouco escolarizados na cidade de São Paulo ${ }^{1}$
}

\author{
The relationship between education and computer \\ use: quantitative aspects of a case study with little \\ schooling adults at Sao Paulo city
}

\section{La relation entre l'éducation et l'utilisation des ordinateurs: aspects quantitatifs d'une étude de cas chez les adultes peu scolarisés dans la ville de Sao}

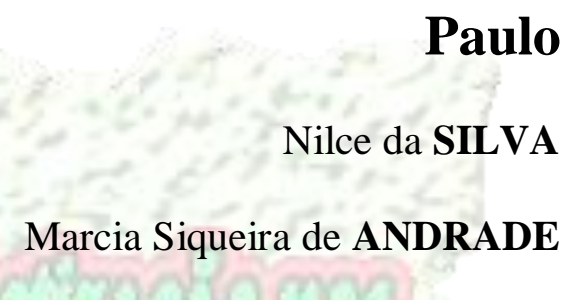

Cleomar de AZEVEDO

\section{RESUMO}

Este artigo trata da relação entre escolaridade e uso do compütador. A partir de pesquisa exploratória, com características quantitativa's e qualitativas, junto a dois grupos de participantes: G1, constituído por alúnos de EJA da cidade de São Paulo, e G2, formado por alunos ém situação de supraescolarização no Quebec, obtivemos elementos sobre a temática em questão. Foram aplicados questionários para a caracterização dos sujeitos envolvidos com o objetivo de relacionar a variável escolaridade e o uso do computador. Realizamos intervenções com observação ativa e entrevistas informais junto a G1. A análise dos dados quantitativos coletados indica que a maioria dos alunos de EJA não se sente à vontade ao falar sobre a cibercultura. Apesar de interessados no assunto, declaravam-se envergonhados por ainda não estarem inseridos neste novo cenário. Constatou-se que os participantes do G2 mostram-se familiarizados com o uso do computador para diversos fins, inclusive o da aprendizagem. Conclui-se que o nível de escolaridade interfere diretamente na utilização do computador, tanto na frequência como na forma, uma vez que quanto maior

\footnotetext{
${ }^{1}$ Em próximo artigo, será apresentada análise dos dados qualitativos coletados neste trabalho de campo.
} 
o grau de escolaridade, maior é a confiança na utilização das ferramentas e aplicativos do computador e ainda que tal temática está no cerne do debate acerca da alfabetização de jovens e adultos e da formação de professores desta modalidade de ensino.

Palavras-chave: escolarização, cibercultura, alfabetização, educação de jovens e adultos, formação de alfabetizadores.

\begin{abstract}
This article is about the relation between education level and computer use. From an exploratory research, with quantitative and qualitative characteristics, with two groups of participants: G1, composed by students in adult education in São Paulo, and G2, formed by students with a lot of school years in Quebec region, we obtained some elements about the thematic in question. Questionnaires were applied to characterize these two groups and carried educative interventions, active observation and informal interviews were realized with G1. The analysis of quantitative data collected indicates that most adult education students in Sao Paulo don't feel comfortable talking about cyberculture. Although they are interested in the subject, they declared ashamed for not being included in this new scenario. It was found that participants from G2 are familiarized with computer use for various purposes, including learning. We concluded that the level of schooling interferes directly with computer use, its frequency and way, and have a lot of number study years gives a greater confidence in tools and applications computer use for students and still that this article's subject is at the heart of the adult's literacy and youths and adults' debate teacher training in this type of education.
\end{abstract}

Index terms: education, cybereulture, literacy, youths and adults literacy, teacher training.

\title{
RÉSUMÉ
}

Cet article aborde la relation entre l'éducation et l'utilisation des ordinateurs. À partir de la recherche exploratoire avec des caractéristiques quantitatives et qualitatives, ainsi que deux groupes de participants: G1, composé par des étudiants d'EJA (éducation de jeunes et d'adultes) de la ville de São Paulo, et G2, formé par des étudiants en situation au- dessus de la scolarité au Québec, nous avons obtenu des informations sur le sujet de la recherche.

Des questionnaires ont été appliqués pour la caractérisation des sujets impliqués afin de faire la liaison entre l'enseignement et utilisation de l'ordinateur. 
Nous avons réalisé des interventions avec l'observation des participants et des entretiens

Les interventions menées avec l'observation des participants et des entretiens informels avec le G1.

L'analyse des données quantitatives collectées indiquent que la plupart des étudiants d'EJA ne se sentent pas l'aise pour parler de la cyberculture.

Malgré, être interessé sur ce sujet, ces personnes ont déclaré qu'ils avaient honte parce qu'ils ne sont pas encore inclus dans ce nouveau scénario.

Il a été constaté que les participants du G2 étaient familier avec l'utilisation des ordinateurs pour des diverses fins, y compris l'apprentissage.

Il est conclu que le niveau de scolarité interfère directement dans l'utilisation de l'ordinateur, en fréquence et en forme, puisque plus le niveau d'éducation est élevé, plus la confiance dans l'utilisation des outils et des applications informatique sont au cœur du débat sur l'alphabétisation des jeunes et adultes et de la formation des enseignants dans ce type d'enseignement.

Mots-clés: scolarité, cyberculture, alphabétisation, éducation des jeunes et d'adultes, formation de professeur d'alphabétisation

\section{Introdução}

O mundo atual é baseado no capital humano; no conhecimento. Neste cenário, a informatização revaloriza as formas de saber_(GORZ, 2005) gerando um fluxo contínuo de informações, dando nova significação cultural e econômica à sociedade. Dito de outro modo, o mundo atual predominantemente utiliza o recurso às tecnologias da informação e comunicação para a troca de informação em formato digital (GOUVEIA e GAIO, 2004) e se encontra marcado pelo uso de computadores.

Neste terreno em que a cibercultura ganha cada vez mais espaço, há que se perseguir uma maior compreensão do letramento, conceito introduzido recentemente no contexto brasileiro, mais precisamente nas áreas de letras e educação. Faz-se necessário enfatizar o fenômeno em seus diferentes aspectos, sem, entretanto, alterarmos o conceito que Soares 
apresentou em 1998, ao afirmar que o letramento é o estado ou condição de indivíduos ou de grupos sociais de sociedades letradas que exercem efetivamente as práticas sociais de leitura e de escrita, participando competentemente de eventos de letramento.

Deste modo, hoje, quando pensamos na Educação de Jovens e Adultos (EJA), assim como em todas as outras modalidades de ensino, não podemos negar que na cidade de São Paulo é muito difícil estar distante do computador. Esta máquina, e tudo que a acompanha, faz parte do cotidiano dos moradores desta grande cidade. Portanto, utilizar-se desta ferramenta implica na promoção de práticas sociais de leitura e escrita. E assim, neste contexto, é válido afirmar que mesmo não sendo alfabetizados, esses adultos que frequentam o EJA estão imersos no universo das novas tecnologias em seu dia a dia, como nos caixas-eletrônicos ou no manuseio de aparelhos celulares.

Sendo assim, enquanto formadores de futuros alfabetizadores, não poderíamos deixar de nos questionar como tem se dado a relação entre alunos de EJA da cidade de São Paulo e o computador, tendo em vista a posição socioeconômica excludente que ocupam e a consequente inserção no sistema escolar brasileiro para que possamos rever nossa atuação-como formadores.

A partir de instrumentos da pesquisa quantitativa e qualitativa, buscamos caminhos que pudessem iluminar esta investigação. Decidimos que, pelo contraste apresentado do ponto de vista social, econômico e educacional, numa primeira etapa desta investigação- a quantitativaestabelecemos um grupo controle na região do Quebec, conhecido 'primeiro mundo', aqui chamado de G2 que, como sabemos, falam de um lugar social diametralmente oposto daquele ocupado pelos alunos de EJA na periferia de São Paulo.

Deste modo, aproximamo-nos de duas realidades: G1, composto por alunos de EJA na São Paulo, alunos de escola noturna da periferia de São 
Paulo; e G2 que se constituiu por francófonos, supraescolarizados alunos em situação socioeconômica estável, com nível técnico ou superior completo, residentes e nascidos na província do Quebec, Canadá.

Tomadas estas providências do ponto de vista metodológico, averiguamos como estes sujeitos - tão distantes socialmente - se relacionam com o computador e com a internet cotidianamente no âmbito das novas práticas de leitura e escrita impostas pelas novas tecnologias das quais trataremos a seguir.

\section{Novas práticas de leitura e de escrita no século XXI}

\section{Um pouco de números e de história}

De acordo com Primo (2007), a escrita em um livro é presa a uma sequência linear. A prática da escrita, para ser compreensível sobre um papel, precisa apresentar esta mesma característica ${ }^{2}$. Contudo, são diversos os exemplos e as situações que nos mostram que o pensamento humano nẩo segue esta linearidade. Há diferentes formas de organização do nosso pensamento. Um exemplo desta organização, que foge ao linear e sé assemelha a uma rede, é associação de palavras pelo seu sentido.

Ainda segundo o referido autor, o Online System (NLS) foi o primeiro sistema hipertextual-coneeito que exploraremos mais adiante criado por Douglas Engelbart em 1968 no Instituto de Pesquisas da Universidade de Stanford. Sete anos depois, surge Bill Gates e Paul Allen com o lançamento da linguagem Basic.

Em 1983, a rede, que contava com menos de 500 computadores, era restrita ao uso militar. Poucos anos depois, em 1987, já existiam 28 mil computadores sem vínculo com o aparato industrial-militar (geralmente

\footnotetext{
${ }^{2}$ Não por isso, podemos nos esquecer de diferentes autores que, com suas obras feitas no papel, escreveram hipertextos. Trata-se de James Joyce, Jorge Luís Borges, Júlio Cortazar, dentro outros, conforme nos apresenta Primo (2007).
} 
conectados às universidades, cuja usabilidade era direcionada a profissionais técnicos e não ao usuário comum). É neste contexto que surgem os $e$-mails.

Outros dados chamam nossa atenção. Há 10 anos havia 23,2 milhões de aparelhos celulares (linhas ativas, mais especificamente) no Brasil. Cinco anos depois, os números subiram brutalmente para 86,2 milhões de celulares; em 2010, os aparelhos já são 185,1 milhões no país. Os dados evidenciam mais do que o crescimento das companhias telefônicas, eles nos indicam um maior acesso às redes de computadores (cf. PRIMO, 2007).

Já na década de 90, de acordo com o mesmo autor, vários fenômenos ocorrem: intensificação das comunicações de dados via telefonia; comunicações mediadas por computador que são concatenadas no âmbitô do world wide web, a Internet (construída a partir de uma linguagem de programação hipertextual: hypertext markup language (HTML); o surgimento dos primeiros provedores de acesso; o aparecimento dos browsers (softwares); a abertura para o e-comércio e a intensificação das atividades de entretenimento. Finalmente, destacamos a linguagem Java criada pela Sun Microsystems (capaz de construir sites dinâmicos).

\section{Os hipertextos}

Parā- compreendermos -0 contexto em que se desenvolveu esta pesquisa- o dos novos letramentos- o conceito de hipertexto é de suma importância.

De acordo com Primo (2007), o termo hipertexto foi usado pela primeira vez por Ted Nelson, no início dos anos 60, como a possibilidade de se ler e escrever de modo não-sequencial, não-linear e que possui vários caminhos pelos quais o leitor pode adentrar para proceder sua leitura e para elaborar sua escrita. É apoiado no conceito de hipermedia que inclui por associação, junto com a escrita, as informações visuais, sonoras, animadas e outras. 
Seis são os critérios dos hipertextos apresentados por Pierre Lévy em seu livro As tecnologias da inteligência (1992). Vejamos quais são eles:

O primeiro princípio é o da metamorfose. Segundo este, a produção escrita tem como tendência se construir permanentemente em direção a uma suposta estabilidade. Entretanto, no hipertexto há uma demanda pela modificação.

Já, o segundo princípio, o da heterogeneidade, indica que a produção escrita se faz a partir de dados e possibilidades diferentes, sem padronização. Ou seja, ela se dá por meio de imagens, sons, textos de diferentes lugares do mundo. Da mesma forma, o processo de leitura passa pelo mesmo princípio: o texto pode ser acessado por pessoas de diferentes locais e lido de distintas maneiras por diferentes motivos.

Com relação ao terceiro princípio, o da multiplicidade e de encaixe das escalas, Lévy destaca que o hipertexto se organiza de forma "fráctal" e com efeito cascata. Dito de outro modo, uma conexão pode nos encaminhar a uma multiplicidade de novas conexões.

O princípio de exterioridade, que compreende que a internet em si não tem um motor capaz de se gerar, explicita a relação entre esta rede e o ser humano, responsável pelo seu movimento.

Lévy nos traz um quinto princípio, o da topologia. Nos hipertextos, tudo funciona por proximidade, por vizinhança, em uma rede que é o próprio espaço.

Finalmente, no sexto e último princípio, nomeado como mobilidade dos centros, entendemos que a rede tem uma estrutura rizomática, com múltiplos móveis, nós, centros de significação e possibilidades de caminho de leituras e de escritas.

Sendo assim, no computador, o espaço de escrita é a tela, ou a "janela"; ao contrário do que ocorre quando o espaço da escrita são as páginas do códice. Quem escreve ou lê a escrita eletrônica tem acesso, a cada momento, apenas ao que é exposto no espaço da tela: o que está escrito 
antes ou depois fica oculto (embora haja a possibilidade de ver mais de uma tela ao mesmo tempo, exibindo uma janela ao lado de outra, mas sempre em número limitado). O que é mais importante, porém, é que a escrita na tela possibilita a criação de um (hiper)texto fundamentalmente diferente do texto no papel - o chamado hipertexto que é "um texto móvel, caleidoscópico, que apresenta suas facetas, gira, dobra-se e desdobra-se à vontade frente ao leitor” (LÉVY, 1999, p. 56). O texto no papel é escrito e é lido linearmente, sequencialmente - da esquerda para a direita, de cima para baixo, uma página após a outra; o texto na tela - o hipertexto - é escrito e é lido de forma multilinear, multi-sequencial, acionando-se links ou nós que vão trazendo telas numa multiplicidade de possibilidades, sem que haja uma ordem predefinida.

Na obra "Interação mediada por computador", Primo (2007) destaca dois tipos básicos de hipertextos: os "exploratórios" (em que o usuário pode alterar muito pouco o conteúdo do texto: Internet) e os "construtivos" (nos quais o usuário tem a possibilidade de alterar boa parte do conteúdo do texto: $M u d s)$.

O hipertexto não é apenas uma rede de microtextos, mas simum grande metatexto de geometria variável, com gavetas, com dobras. Um parágrafo_pode aparecer ou desaparecer sob uma palavra, três capítulos sob uma palavra ou parágrafo, um pequeno ensaio sob uma das palavras destes capítulos, e assim virtualmente sem fim, de fundo falso em fundo falso. Ao ritmo regular da página se sucede o movimento perpétuo de dobramento e desdobramento de um texto caleidoscópico.

Pode-se concluir que não é somente este novo espaço de escrita; a tela, que gera um novo letramento, para isso também contribui os mecanismos de produção, reprodução e difusão da escrita e da leitura. Segundo Eco (1995), os eventos de letramento que ocorrem com a intermediação da Internet exigem novas práticas e novas habilidades de leitura e de escrita: precisamos de uma nova forma de competência crítica, 
uma ainda desconhecida arte de seleção e eliminação de informação, em síntese, uma nova sabedoria.

Finalmente, de acordo com os autores até então consultados, podemos afirmar que o hipertexto reproduz a forma do pensamento humano.

Tendo feito estas considerações acerca do hipertexto, com o qual os sujeitos desta pesquisa se confrontam cotidianamente, passemos à caracterização dos sujeitos desta pesquisa e verificar até que ponto pertencer ao conhecido Primeiro Mundo influencia ou não no uso das novas tecnologias. Ou seja, vejamos, de um ponto de vista quantitativo, as principais diferenças e similaridades encontradas entre as práticas tecnológicas digitais de leitura e escrita dos grupos estudados frente aos hipertextos aos quais têm sido expostos os sujeitos desta pesquisá no cotidiano em São Paulo e em Quebec.

\section{Método}

\section{Participantes}

Participaram deste momento da pesquisa dois grupos: o primeiro (G1) constituído por 234 alunos de Educação de Jovens e Adultos da cidade de São Paulo, Brasil em processo de alfabetização e o segundo (G2), formado pôr 18 alunos em situação de supraescolarização, da província do Quebec, Canadá.

\section{Instrumentos e procedimentos}

Foi aplicado o mesmo questionário para os participantes do Brasil (G1) e para os estudantes de Quebec (G2), com as seguintes questões: gênero do respondente, faixa etária, anos de escolarização e lista de possibilidades de usos do computador.

Junto ao grupo 1, além do referido instrumento, aplicado anonimamente e, muitas vezes, preenchido pelo próprio pesquisador tendo em vista a dificuldade de leitura e escrita do respondente, foram também 
realizadas intervenções educativas e observação ativa em 10 salas de EJA entre os meses de abril e junho de 2011, com elaboração de relatórios pelos nossos alunos- pesquisadores (alunos do curso de Pedagogia da USP em situação de estágio ou de estudos independentes, instrumentos que nos forneceu dados qualitativos que estão sendo analisados no momento e que, conforme anunciamos na introdução deste texto, não serão tratados neste artigo.

O referido questionário foi traduzido para a língua italiana ${ }^{3}$ e aplicado aos participantes de Quebec nos meses de fevereiro e março de 2011. Tais sujeitos, adultos cuja língua materna é o francês, estudam italiano por motivo de futura viagem à Itália. O local escolhido para a aplicação foi um Centro de Loisir na cidade de Trois-Rivières, com, aproximadamente, 130.000 habitantes, no Quebec, Canadá.

Em seguida, tabulamos os dados coletados, calculamos as tenđências encontradas e fizemos gráficos acerca dos resultados obtidos para facilitar a nossa compreensão sobre a relação entre as variáveis estudadas, visualizarmos as tendências das respostas obtidas e evidenciar o contraste entre os dados obtidos no Canadá e no Brasil.

\section{Resultados e discussão}

Dos participantes desta pesquisa, $66 \%$ pertencem ao sexo feminino, ou seja, 166 são mulheres. Enquanto que 86 dos nossos sujeitos são homens. O primeiro gráfico nos mostra a distribuição dos entrevistados por gênero:

\footnotetext{
${ }^{3}$ Tivemos o cuidado de traduzir o questionário para o italiano para que incomodássemos o menos possível o curso de italiano que os alunos estavam frequentando e mesmo pudessem aprender vocabulário por meio do instrumento de pesquisa.
} 


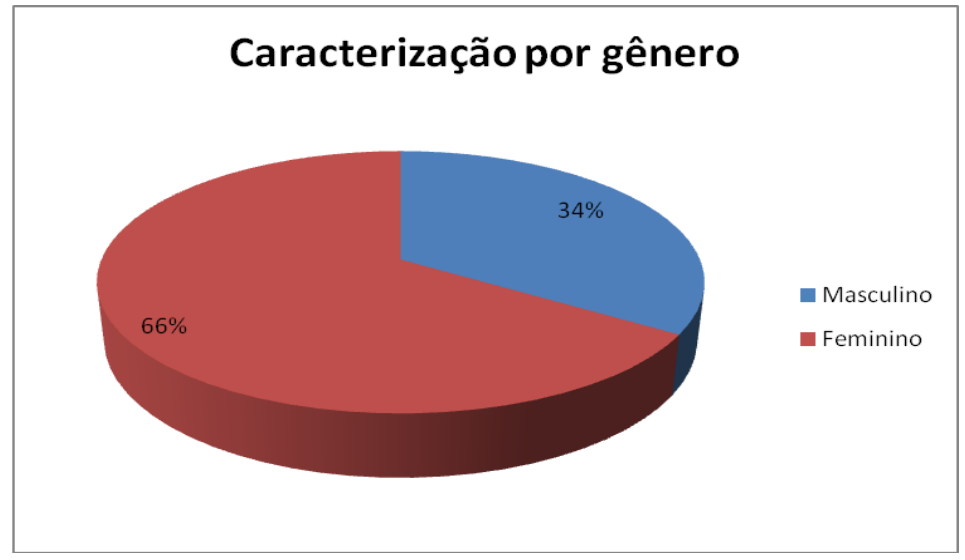

Com relação ao nível de escolaridade alcançado pelos sujeitos deste trabalho, temos a seguinte caracterização:

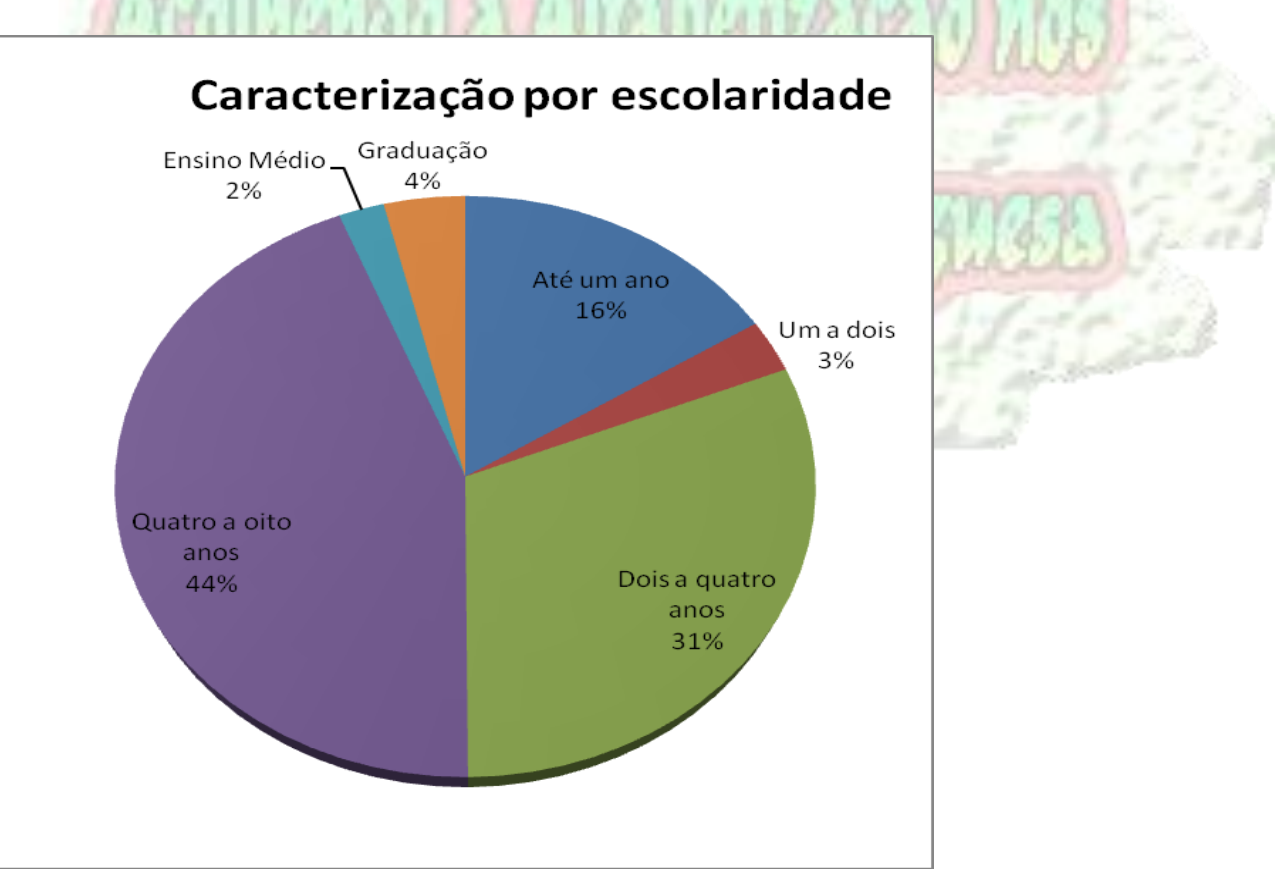

Aqui, vale à pena ressaltar que os $6 \%$ dos envolvidos nesta pesquisa que possuem Ensino Médio técnico-profissionalizante são os quebequenses. Ou seja, a grande maioria dos nossos sujeitos, alunos de EJA, perfaz 94\% de estudantes com menos de oito anos de estudos. 
O próximo gráfico nos mostra a distribuição dos usuários por idade. Observemos:

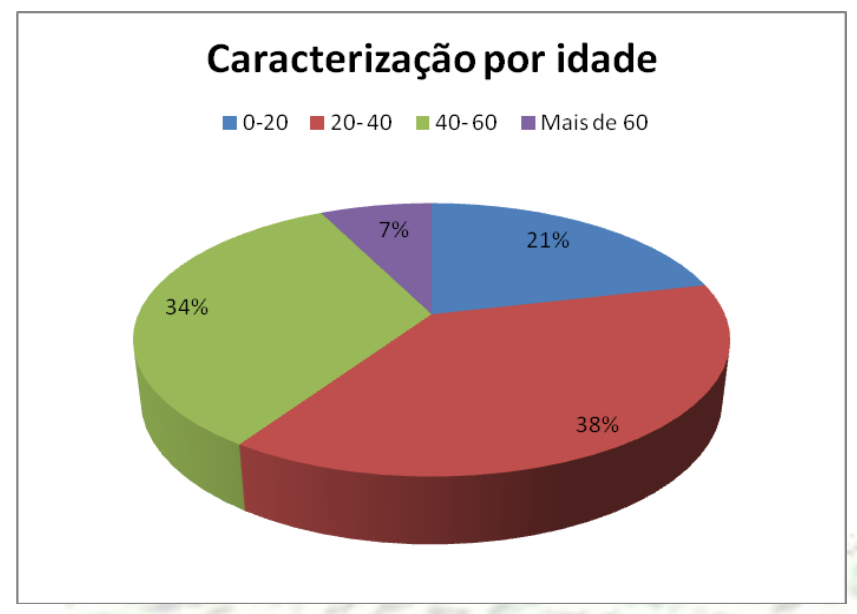

Conforme podemos observar, a moda dos dados coletados nesta pesquisa se concentra na faixa de idade entre 20 e 40 anos. Já a maior parte dos envolvidos do nosso estudo se situam na faixa etária que também é economicamente ativa, ou seja, entre 20 e 60 anos. Apenas $7 \%$ dos sujeitos com os quais levantamos estas informações, em torno de 12 pessoas, são considerados como pertencentes à 'terceira idade'.

Depois deste tratamento inicial referente à caracterização dos sujeitos com os quais aplicamos o questionário de caracterização, passamos a distribuição dos resultados obtidos em função da utilização do computador.

Nestes cruzamentos de variáveis, vejamos a distribuição da utilização dos aplicativos de computadores em função do gênero dos sujeitos desta pesquisa. 


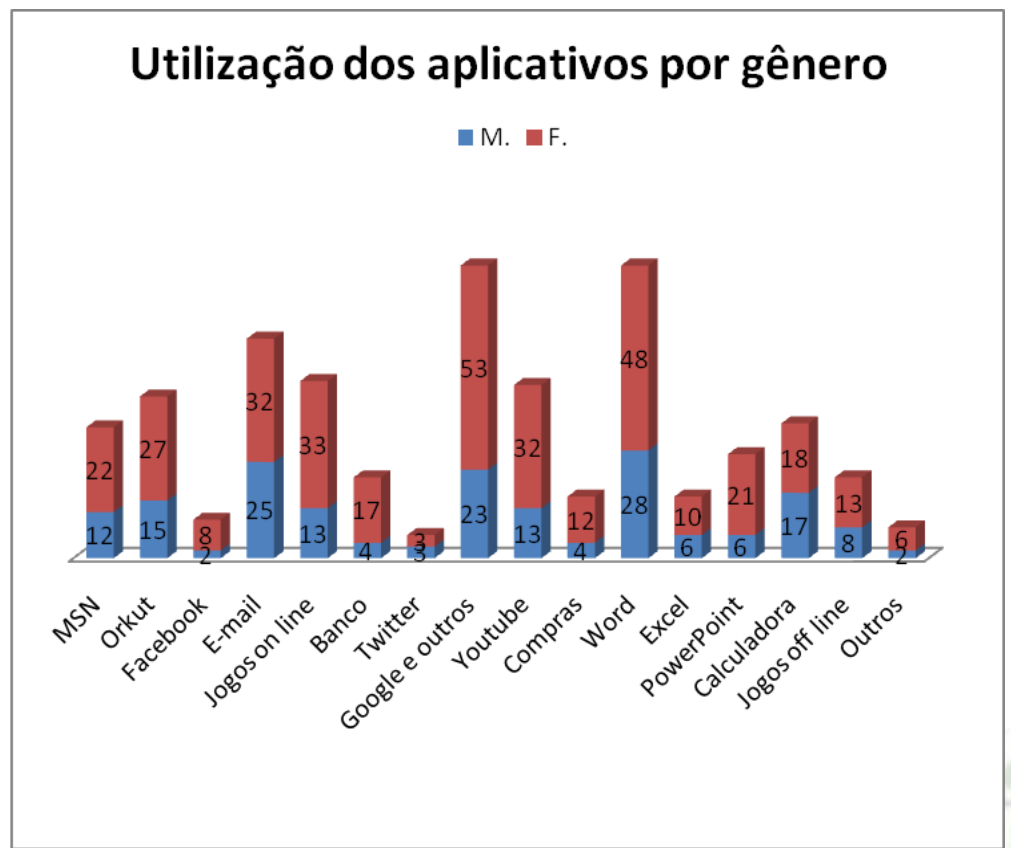

Verificamos neste gráfico de colunas que o Facebook, jogos on line e sites de banco são predominantesmente de interesse feminino, assim como, a utilização do programa word.

O Twitter, o menos usado dentre os aplicativos apresentados, é utilizado igualmente entre homens e mulheres. Assemelha-se a esta equidade, o uso que os sujeitos desta pesquisa fazem da calculadora.

O próximo gráfico desta série apresenta a distribuição em função da idade dos_usuários e o uso que fazem do PC. 


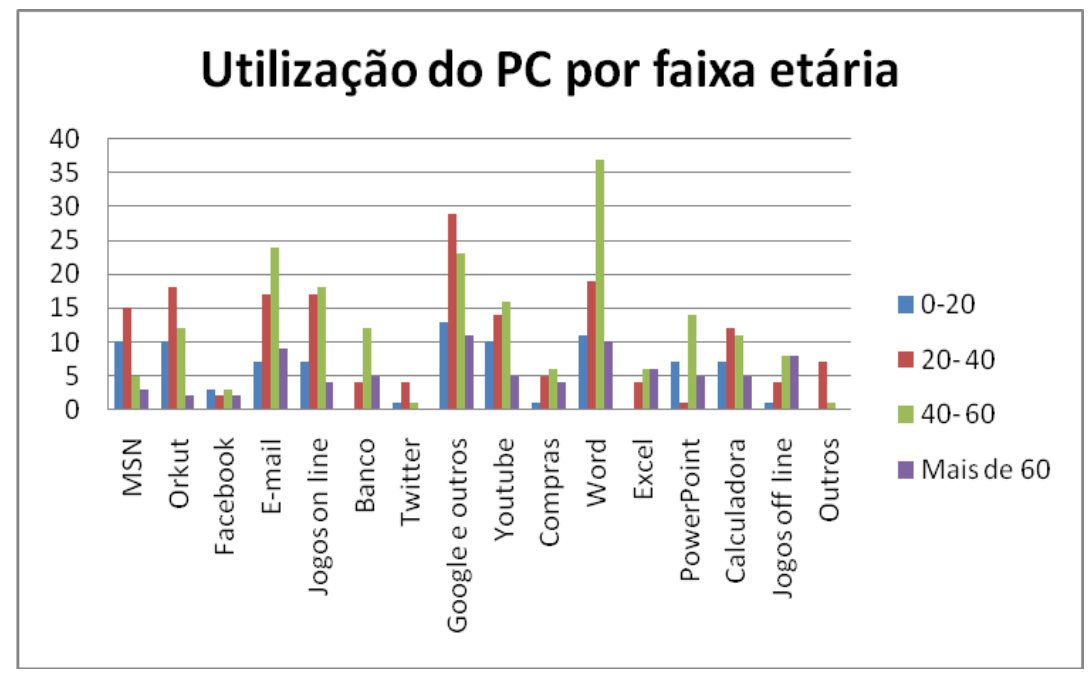

Observa-se que o word, o e-mail e o PowerPoint são utilizados com maior frequencia pelos sujeitos com idade entre 40 e 60 anos, idade produtiva conforme já assinalamos. Por outro lado, as pessoas entre 20 e 40 anos se encontram com maior peso no MSN, no Orkut, nos sites de busca e no uso da calculadora. E, os mais jovens, adultos até 20 anos (todos alunos do EJA no caso desta pesquisa), fazem uso do Orkut, do MSN, sites de busca, acesso ao YouTube, no PowerPoint; sendo inexpressivos nos jogos off line, na realização de compras e no uso do banco. Ou seja, constata-sé que o site de relacionamento (Orkut), é desconhecido pelos canandenses envolvidos nesta pesquisa e é exclusivamente frequentado pelos usuários brasileiros. $\Theta$ Facebook é um site mais globalizado, apesar de ser mais utilizado pelos quebequenses possivelmente pelo nível de escolaridade dos mesmos.

E, assim, ao analisarmos estes gráficos, podemos notar que de maneira global, a utilização feita pelos sujeitos desta pesquisa se concentra nos sites de busca e pesquisa (Google), no editor de texto (Word) e no $e$ mail.

Abaixo, temos um último gráfico que apresenta a utilização do computador tendo em vista os anos de escola frequentados pelos sujeitos desta investigação. E é justamente aqui que notamos que ter nascido e 
crescido no Quebec implica em ter maior contato, nos dias atuais, com os novos letramentos proporcionados pelo uso do computador.

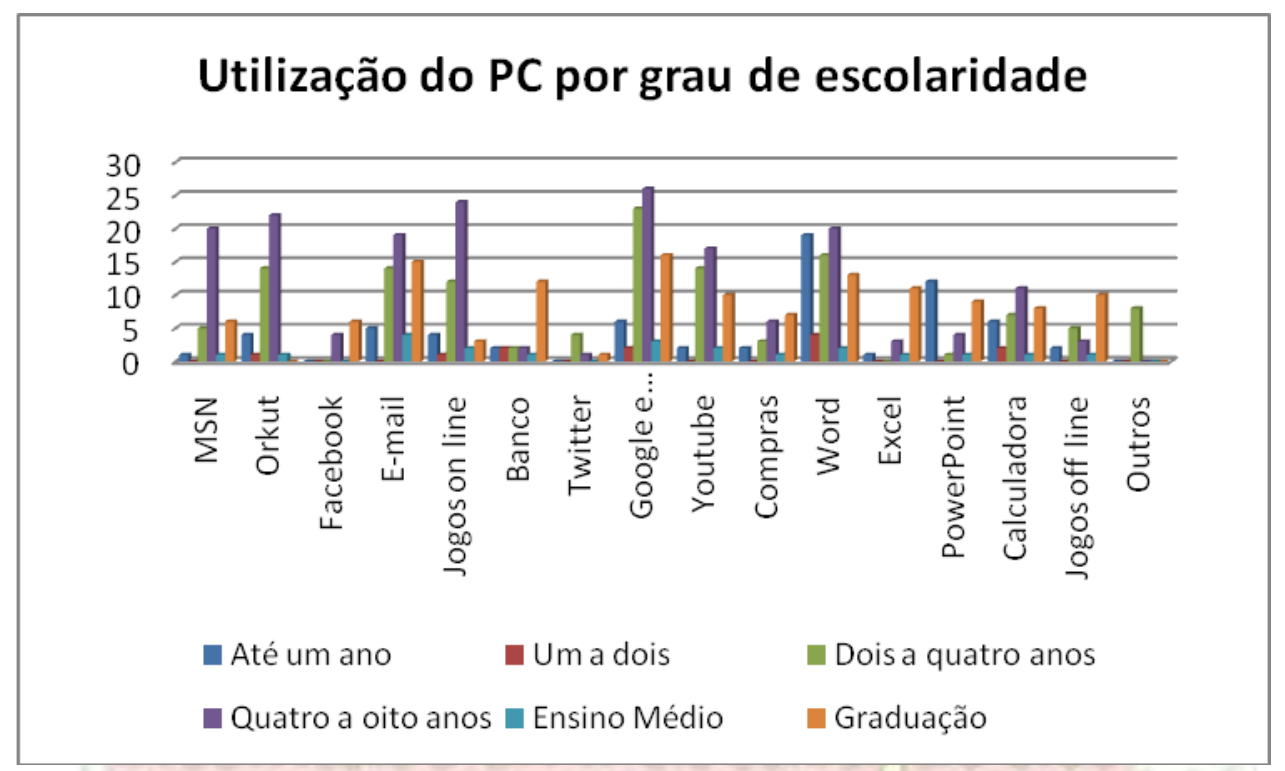

Pessoas com até um ano de escola têm muito pouco acesso quanto às alternativas apresentadas. $\mathrm{O}$ mesmo podemos dizer quanto aos alunos com até dois anos de escolaridade. Entretanto, estes fazem maior uso da calculadora que os seus colegas menos escolarizados.

Interessante notar que o próximo intervalo de idade que utilizamos nesta caracterização, ter estudado entre dois e quatro anos, parece ser um momento de passagem e de abertura de possibilidade para o uso das alternativas aqui apresentadas vinculadas ao computador.

E, finalmente, notamos que, apesar de serem minoria neste população estudada, os alunos quebequenses apresentam maioria, relativo e absoluta, no que se refere ao uso de e-mail, banco, sites de busca e compras. Interessante constatar que são também estes alunos mais escolarizados que se apresentam como usuários de jogos off line. 
Diante destas constatações, inferimos que quanto maior o grau de escolaridade, maior é a confiança na utilização das ferramentas e aplicativos do computador.

\section{Considerações finais}

Sugerimos que se pluralize a palavra letramento, reconhecendo que diferentes tecnologias de escrita criam diferentes letramentos. Na realidade, a necessidade de pluralização da palavra letramento e, portanto, do fenômeno que ela designa, já vem sendo reconhecida internacionalmente. Tendo como seus objetivos designar diferentes efeitos cognitivos, culturais e sociais em função ora dos contextos de interação com a palavra escrita, ora em função de variadas e múltiplas formas de interação com o mundo não só a palavra escrita, mas também a comunicação visual, audjitiva, espacial.

Tendo em vista a proposta deste artigo, de discutir apenas os dados quantitativos coletados, afirmamos que diferentes espaços sociais de escrita e diferentes mecanismos de produção, reprodução e difusão da escrita da mesma resultam em diferentes letramentos e diferentes possibilidades de acesso aos mesmos e que tal distribuição de saberes é_vinculada estreitamente à distribuição de riquezas no âmbito planetário.

Sendo assim, considera-se que, à luz de que o letramento é fenômeno plural, historicamente e contemporaneamente, ou seja, existem diferentes letramentos ao longo do tempo assim como diferentes letramentos no nosso tempo, faz-se mister a análise dos relatórios feitos pelos alunospesquisadores desta investigação que nos trarão, juntos com o estudo dos dados quantitativos aqui apresentados, indicadores preciosos para a elaboração de novas pesquisas acerca da relação entre escolarização e computador, tão importantes para nossos alunos de EJA assim como para a formação inicial ou em serviço de professores alfabetizadores. 


\section{Referências Bibliográficas}

ECO, U. Os limites da interpretação. São Paulo: Perspectiva, 1995.

GORZ, A. O imaterial: conhecimento, valor e capital. São Paulo: Annablume, 2005.

GOUVEIA, L. B. e GAIO, S. (orgs.). Sociedade da Informação: balanço e implicações. Porto: Edições Universidade Fernando Pessoa, 2004.

LÉVI, P.. As tecnologias da inteligência: o futuro do pensamento na era da informática. Lisboa: Instituto Piaget, 1992.

PRIMO, A.. Interação mediada por computador. Rio Grande do Sul: Edição Sulina, 2007.

SOARES, M.. Letramento: um tema em três gêneros. Belo Horizonte: Autêntica, 1998.

Novas Práticas de leitura e escrita: letramento na cibercultura. Revista Educação e Sociedade, Campinas, vol. 23, n. 81, p. 143-160, dez. 2002 143. Disponível em http://www.cedes.unicamp.br Acessado em 11 de abril de 2011.

\section{Autoras:}

\section{Nilce da SILVA}

Doutora em Educação pela Universidade de São Paulo e docente da Faculdade de Educação da Universidade de São Paulo.

Endereço residencial: Rua Antonieta Leitão, 209. Ap. 12. Freguesia do Ó. São Paulo. SP- Brasil. CEP: 02925- 160.

Endereço institucional: Av. da Universidade, 308. Bloco A. Sala 111. Butantã, São Paulo. SP- Brasil. CEP: CEP 05508-900.

Contato: nilce@usp.br

Telefone: (11) 3091-3099 


\section{Cleomar AZEVEDO}

Doutora em Educação pela Pontifícia Universidade Católica de São Paulo e pós-doutora em Ciências Sociais pela Pontifícia Universidade Católica de São Paulo. Docente do Programa de Pós-graduação Stricto Sensu em Psicologia Educacional do Centro Universitário FIEO.

Endereço residencial: Rua Jaguaraoi, 178. Cidade Vargas. São Paulo, SP Brasil. CEP: 043118-040.

Endereço institucional: Av. Franz Voegeli, 300. Vila Yara. Osasco, SP Brasil. CEP: 06020-190.

Contato: cleomar.azevedo@uol.com.br

\section{Márcia Siqueira de ANDRADE}

Doutora em Psicologia da Educação pela Pontifícia Universidade Católica de São Paulo e coordenadora do Programa de Pós-graduação Stricto Sensu em Psicologia Educacional do Centro Universitário FIEO.

Endereço residencial: Rua Manoel Guedes, 339. 12o andar. Jardim Europa. São Paulo, SP - Brasil. CEP: 04536-070

Endereço institucional: Av. Franz Voegeli, 300, Vila Yara. Osasco, SPBrasil. CEP: 06020-190.

Contato:mandrade@unifieo.br

Texto recebido em maio de 2011.

Texto aprovado para publicação em janeiro de 2012.

\section{Como citar este texto:}

SILVA, N.; ANDRANDE, M. S., AZEVEDO, C. de. A relação entre escolaridade e uso do computador: aspectos quantitativos de um estudo de caso junto a adultos pouco escolarizados na cidade de São Paulo Os saberes docentes no processo de alfabetização. Revista Acolhendo a alfabetização nos países de língua portuguesa, Brasil, São Paulo, volume $1, \mathrm{n}^{\circ} .12$, p. 07-24, Mar. 2012. Disponível em: 〈http://www.acoalfaplp.net>. 